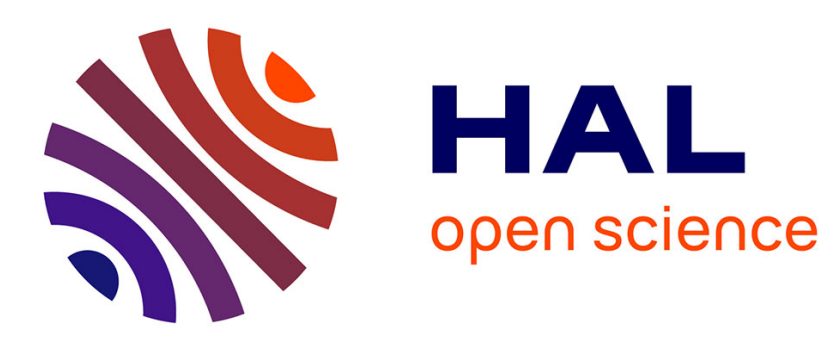

\title{
Design and Evaluation of a Real-World Virtual Environment for Architecture and Urban Planning
}

George Drettakis, Maria Roussou, Alex Reche, Nicolas Tsingos

\section{To cite this version:}

George Drettakis, Maria Roussou, Alex Reche, Nicolas Tsingos. Design and Evaluation of a Real-World Virtual Environment for Architecture and Urban Planning. Presence: Teleoperators and Virtual Environments, 2007, 16 (3), 10.1162/pres.16.3.318 . inria-00607261

\section{HAL Id: inria-00607261 https://hal.inria.fr/inria-00607261}

Submitted on 8 Jul 2011

HAL is a multi-disciplinary open access archive for the deposit and dissemination of scientific research documents, whether they are published or not. The documents may come from teaching and research institutions in France or abroad, or from public or private research centers.
L'archive ouverte pluridisciplinaire HAL, est destinée au dépôt et à la diffusion de documents scientifiques de niveau recherche, publiés ou non, émanant des établissements d'enseignement et de recherche français ou étrangers, des laboratoires publics ou privés. 


\title{
Design and Evaluation of a Real-World Virtual Environment for Architecture and Urban Planning
}

\author{
George Drettakis $^{1 *} \quad$ Maria Roussou ${ }^{2 \dagger} \quad$ Alex Reche $^{1,3, *}$ \\ Nicolas Tsingos ${ }^{1, *}$ \\ ${ }^{1}$ REVES/INRIA Sophia-Antipolis, FRANCE, \\ ${ }^{2}$ University College London, UK, ${ }^{3}$ CSTB, France
}

May 8, 2006

\begin{abstract}
In this paper we present a user-centered design approach to the development of a Virtual Environment (VE), by utilizing an iterative, user-informed process throughout the entire design and development cycle. A preliminary survey was first undertaken with endusers, i.e., architects, chief engineers and decision makers of a real-world architectural and urban planning project, followed by a study of the traditional workflow employed. We then determined the elements required to make the VE useful in the real-world setting, choosing appropriate graphical and auditory techniques to develop audiovisual VEs with a high level of realism. Our user-centered design approach guided the development of an appropriate interface and an evaluation methodology to test the overall usability of the system. The VE was evaluated both in the laboratory and, most importantly, in the users' natural work environments. In this study we present the choices we made as part of the design and evaluation methodologies employed, which successfully combined research goals with those of a real-world project.

Among other results, this evaluation suggests that involving users and designers from the beginning improves the effectiveness of the VE in the context of the real world urban planning project. Furthermore, it demonstrates that appropriate levels of realism, in particular spatialized 3D sound, high-detail vegetation and shadows, as well as the presence of rendered crowds, are significant for the design process and for communicating about designs; they respectively enable better appreciation of overall ambience of the VE, perception of space and physical objects as well as the sense of scale. We believe this study is of interest to VE researchers, designers and practitioners, as well as professionals interested in using VR in their workplace.
\end{abstract}

*e-mail: $\{$ George.Drettakis $\|$ Alex.Reche $\|$ Nicolas.Tsingos $\} @$ sophia.inria.fr

†e-mail: M.Roussou@cs.ucl.ac.uk 


\section{Introduction}

Many of the Virtual Reality (VR) applications developed today are products of research that are either prototypes created within very specific contexts or are used for presentation purposes. Despite the promise and the development activity of over two decades, the number of real-world applications has remained small. The issues regarding the deployment of VR in everyday work contexts have been discussed many times and continue to revolve around the familiar practical difficulties: setting up special and costly hardware within facilities that are not easily transportable, requiring special teams of developers and maintenance staff, but also providing the high-level tools that will support users in their complex tasks (Neale, Cobb, \& Wilson, 2002) and can succeed in establishing a collaborative VR work environment amongst individuals of different disciplines (Mackay \& Fayard, 1997). Some specific sectors, such as the oil and gas or the automotive industry, have already firmly established design processes in which VR has an integrated role. For typical urban planning and architecture projects, however, VR has not found widespread use.

Experienced practitioners in the field of VR have indicated that to work effectively in a virtual environment (VE), the application content must include the ability to access or change environmental/system/meta parameters, create and manipulate particular objects, perform analyses, and export changes to permanent storage (Sowizral et al., 1995). While the current state of VE development has advanced its techniques to support these tasks, rarely does one find complete VEs that achieve both a high-quality realistic, immersive real-time environment and the level of interactivity required to carry out sufficiently complex real-world tasks.

The main goal of our study was to design, develop, and evaluate an interactive VE environment (see Fig. 1) with a high level of audiovisual realism in the context of a real-world application, using a user-centered methodology.

We chose the domains of architectural design and urban planning (UP), where we considered both realism, due to the representational nature of the work, and interactivity to be requirements of the work process. A detailed user requirements analysis with architects and urban planners (Roussou, Sideris, et al., 2004) confirmed the suitability of our choice and led to a thorough study of the existing workflow in these domains. A key element throughout this work has been the establishment of a close collaboration with the end-users of a real-world urban planning project, involving the redesign of public spaces as part of the construction of a new Tramway in the city of Nice in France.

\section{Related Work}

Virtual reality development for architectural design and urban planning applications can be roughly grouped into two categories: applications that are used to design and display detailed 3D CAD models of architectural spaces/structures and rapid prototyping systems. 


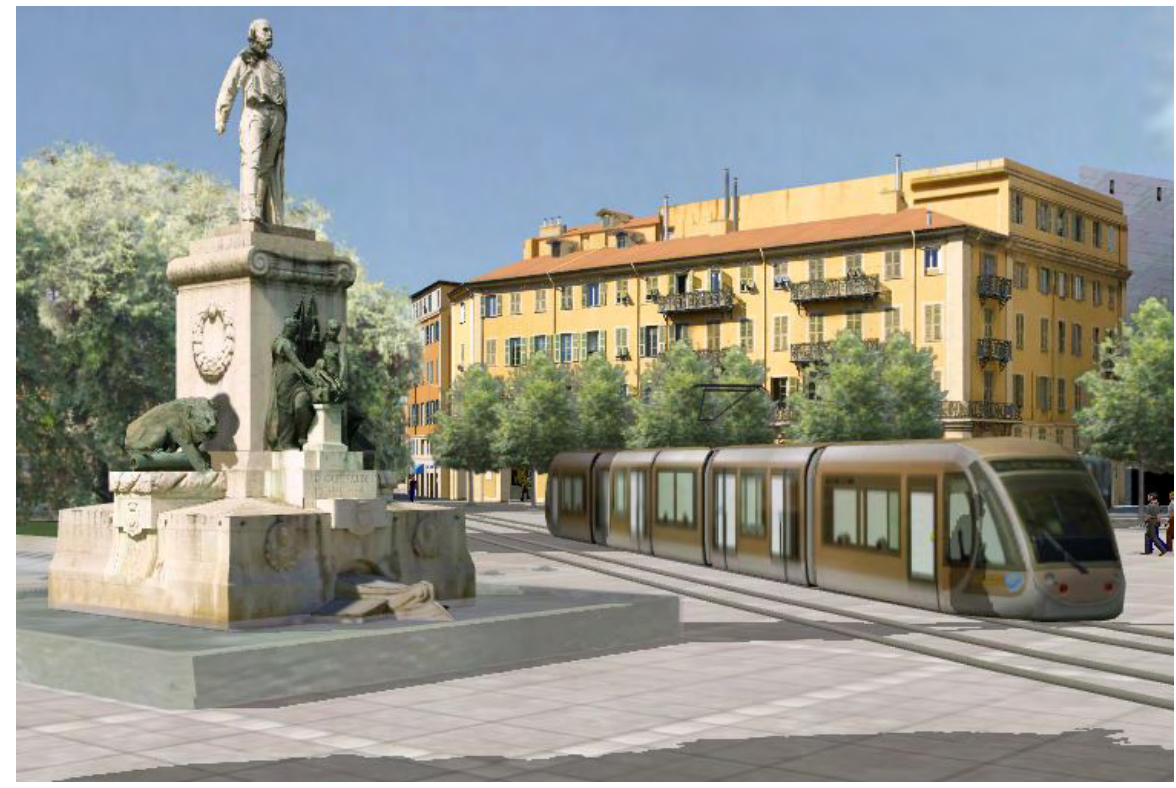

Figure 1: The Virtual Environment of Place Garibaldi in Nice, France, constructed for the study of a future Tramway project.

In the first case, the challenge has been to visualize large data sets in as photorealistic a fashion as possible. These environments are mostly used for presentation, recreation, and educational purposes (e.g. review of architecture before it is actually built, cultural heritage reconstructions, 3D entertainment rides, etc.) where complex 3D spaces are constructed so they can be explored in walkthroughs (Brooks, 1986; Houston, Niederauer, Agrawala, \& Humphreys, 2004). The majority of these projects allow for little to no interactivity beyond the user's ability to freely navigate about the environment.

On the other hand, the virtual prototyping environments allow immersive VR to be used in earlier phases of a design process and are thus designed to incorporate a higher level of interactivity and object manipulability. In most cases, these capabilities are implemented at the expense of visual realism, as they have been developed by computer scientists in order to further advance research in VR tools. Furthermore, most of these environments have not been used in real-world situations. Nevertheless, many interesting ideas have been introduced by architectural prototyping projects that we can draw from. The CALVIN project (Leigh, Johnson, Vasilakis, \& DeFanti, 1996), for example, introduced the idea of different perspectives, the mortal (ground-level) viewpoint and the deity (global above-ground) viewpoint, either of which users can assume in order to interact collaboratively in designing a space in VR. In a more applied and realworld context, the Virtual Los Angeles project (Jepson \& Friedman, 1998) achieved impressive visualizations of urban environments; the results reported here could easily be integrated into such a system.

Augmented reality projects related to construction and urban planning have also 
been studied. Systems such as the Augmented Round Table (Broll, Stoerring, \& Mottram, 2003) or Build-IT (Rauterberg et al., 1997), concentrate more on the user interface aspects of such projects. The work of Ishii's group (Ishii et al., 2002; Ben-Joseph, Ishii, Underkoffler, Piper, \& Yeung, 2001) is a very interesting study in the combination of physical models and computer augmentation, involving both computer scientists and architects. While this body of work is intriguing, we have made the choice to work exclusively with synthetic environments, allowing a more immersive approach and avoiding the need for complex calibration between real and virtual elements.

Architects have long used specialized 3D commercial tools such as Autodesk Revit ${ }^{1}$ and ArchiCAD ${ }^{2}$. However, the visualization, realism and immersive capabilities of these packages are currently limited, while audio support is completely absent. In the long term, we hope that some of the findings described here will be incorporated in integrated versions of such systems.

\section{Design}

The basic premise of our VE design approach has been to engage architects, designers and decision makers from the first steps of the design. Implementing such a usercentered approach requires collecting and analyzing as much information about our users as possible, through a detailed user requirements process (Roussou, Sideris, et al., 2004) and a deep understanding of how they work.

The city of Nice and the Greater Nice-Cote d'Azur Urban Community (CANCA) recently decided to build a Tramway. The project involves $8 \mathrm{~km}$ of rail in the most dense parts of the city, requiring the re-design of several open spaces such as the main city squares, "Place Garibaldi" and "Place Massena". We established a working relationship with the officials and the company of architects in charge of the project. Initially, we presented a simple VE prototype of a section of "Place Massena" to the "Mission Tramway", the organization in charge of the overall project (images can be seen in (Roussou, Drettakis, Tsingos, Reche, \& Gallo, 2004)).

The result of this contact led to a closer collaboration with the architects on the redesign of "Place Garibaldi", and enabled us to gain access to all the project data. The architectural design of this square was of major importance, since the "Place Garibaldi" is a historic landmark and, according to many "the most beautiful square of the city". As such, many stakeholders participated in the decision making process: local elected officials (principally the mayor), the officials of the city council in charge of open spaces and public works, as well as higher state authorities at a national level who generally have a definitive say in any modification of a historical space. There is also a public consultation which started at the beginning and continues throughout the design process.

Our collaboration was founded on the principle of mutual benefit. We were inter-

\footnotetext{
${ }^{1}$ Revit: Autodesk corporation, http://www.autodesk.com/.

${ }^{2}$ ArchiCAD: Graphisoft corporation, http://www.graphisoft.com/.
} 

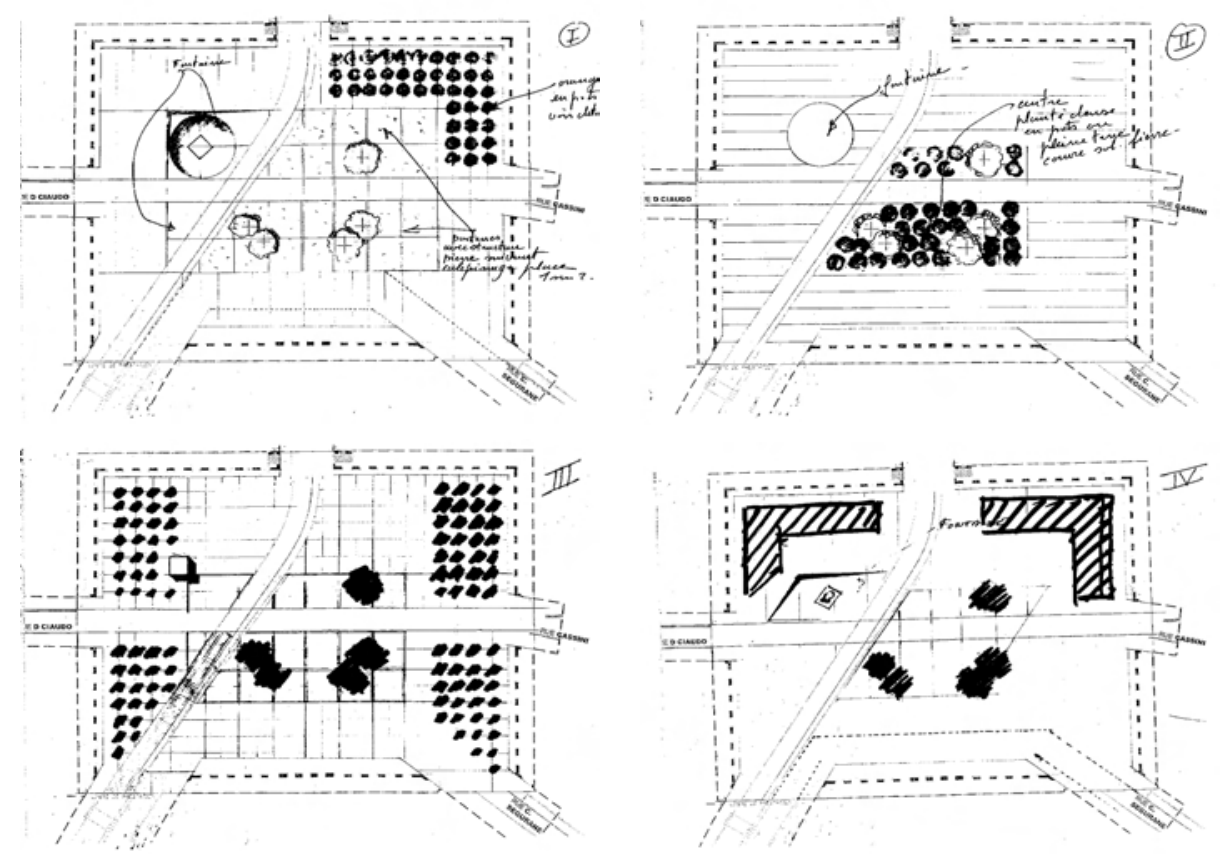

Figure 2: Fast architectural sketches of Place Garibaldi. Black circles correspond to trees; the curved tramway line is shown passing through the square. The large existing oaks are also shown, as well as different options for the statue, in a round or square casing.

ested in studying and understanding the workflow to allow us to design novel VE tools that combine realism and interactivity, and to apply them in a real-world setting. The architects and decision makers of the Mission Tramway were interested in using the resulting interactive VE as an aid in decision making and brainstorming, as well as a presentation tool.

\subsection{Study of End-User Design Workflow}

Multiple discussions and the study of the architects' workflow allowed us to understand the architectural design process and how decisions were made. In particular, for the re-design of the square, several different concepts were proposed, with significant variations: a "Place d'armes" (military, "stone-only" square) in which no additional vegetation was to be allowed; a modern design, with additional vegetation; a more traditional design, with additional vegetation. The architects had a complex balancing act to follow. According to our interviews, they spent a while debating in numerous meetings the different merits of each choice, without advancing much.

The initial design process took place mainly between the municipal administration and the architects. At this stage, architects used simple fast "sketches" to communicate their ideas and the different options (examples shown in Fig. 2). Using this initial stage 

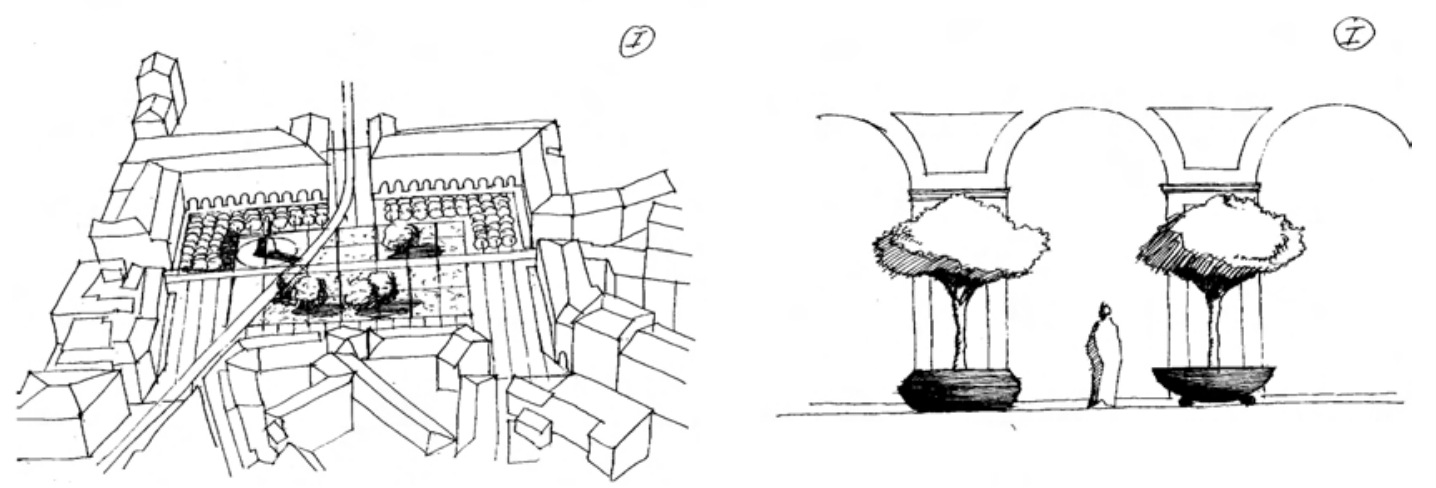

Figure 3: (Left) Perspectives can be used for an overall view of the design. (Right) More involved perspectives can be used to illustrate specific details in the scene.

where they iterate over many experimental sketches on paper, the architects get an overall feel for the design, and sometimes will draw details of part of the site to capture the essence of specific elements, or add humans to give a sense of scale (Fig. 3).

The next stage is the production of photo-montages which are shown to the decision makers and elected officials (Fig. 4). These montages are used to achieve agreement by the different parties and, after this process, the overall "look and feel" of the design converges (i.e., the overall "stone look" of the square, the fact that the trees and the statues are maintained, etc.).

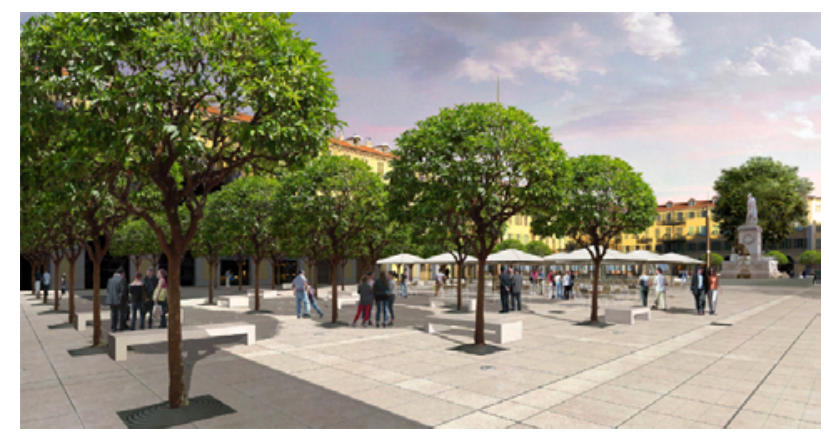

Figure 4: Detailed photo-montages are used to present the project to decision makers.

\subsection{Development of the Realistic VE}

Urban planning scenes include existing elements which do not change (such as building facades, etc.), but also the elements of the new planned space. To be useful as a design and presentation aid, a convincing level of realism needs to be achieved in the VE, both for the representation of the existing buildings and for the new elements that will be added. In this context, realism includes high-quality geometry and textures for buildings, high-quality models and display for vegetation, accurate and consistent lighting 
and relighting with shadows, vehicles and traffic simulation, population with individual and crowd animation with simulated behavior, accurate 3D sound rendering etc. To be included in a VE, the display/rendering of all of the above needs to be sufficiently fast to still result in acceptable frame rates. In our system, we have chosen to concentrate on a set of enhancements that emerged as important through our initial user needs analysis and for which we were able to provide efficient and appropriate solutions.

In particular, our system, the technical details of which have been presented elsewhere (Drettakis, Roussou, Tsingos, Reche, \& Gallo, 2004; Roussou, Drettakis, et al., 2004), provides solutions for photographic capture of existing buildings, shadows, display of vegetation, 3D sound and crowds. We have used novel image-based reconstruction techniques to provide accurate capture of buildings at a medium scale (i.e., the size of a $200 \mathrm{~m} \times 200 \mathrm{~m}$ square in a city), including high-quality textures and moderately complex geometry. We have also adapted perspective shadow maps (Stamminger \& Drettakis, 2002) for use in a VE system, allowing the display of high-quality sharp shadows in real time. Our solution for display of vegetation is based on a mixed approach using point-based rendering and polygons (Deussen, Colditz, Stamminger, \& Drettakis, 2002), which we adapted to our VE display system. This allowed display of 70 trees modelled with 80,000 polygons, using a level-of-detail switching between points and polygons. As a result there is fluid display of trees, while providing highquality, polygon-based display when the user moves closer. We have also developed a novel solution for rendering of high-quality spatialized 3D sound (Tsingos, Gallo, \& Drettakis, 2004), which allows spatialization of a large number (around 300) of sound sources, enabling the use of true 3D sound in complex outdoor environments.

Finally, we have added simple crowd simulation to our environments (Tecchia, Loscos, Conroy, \& Chrysanthou, 2001; Tecchia, Loscos, \& Chrysanthou, 2002) allowing the rapid display of a large number of humans, using rule-based flow simulation (Stylianou, Fyrillas, \& Chrysanthou, 2004).

All of these enhancements are included in a complete system, based on the XP (Pape, Imai, Anstey, Roussou, \& DeFanti, 1998) VR authoring layer, built upon OpenGL Performer $^{T M}$ and CAVELib ${ }^{T M}$, where these are added as new classes in the extensible core library; their parameters are all controllable by scripts which can be edited by the artists and programmers developing the VE.

\subsection{Design of the VE Interface}

The design of our interface was inspired by the workflow described in Sect. 3.1. The initial idea was to preserve the "top view" corresponding to the familiar existing workflow (Fig. 5). We also have a ground-level "perspective view" (Fig. 6 (left)), corresponding to that used for photo-montages. Following suggestions by the architects, we also introduced an intermediate "balcony view", shown in Fig. 6 (right), where the viewer is presented with a view as if she were standing on the balcony of one of the surrounding buildings in the square, corresponding to higher level sketches (see Fig. 3). 


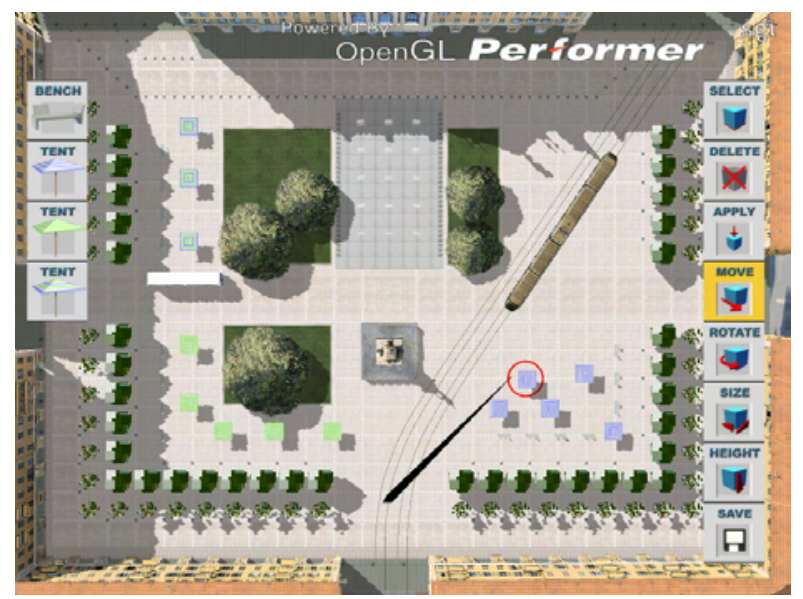

Figure 5: The top view of the VE is displayed with two sets of menus for the insertion and manipulation of dynamic objects. An element (shown with the small circle) is attached to the end of the rod and can be moved and positioned freely.

The user can manipulate dynamic elements in the scene, such as benches, umbrellas etc. in the top view, inspired by the iterative sketches process (Fig. 2). The user has the ability to freely switch between top, perspective and balcony view at any time and perform manipulations in all three.
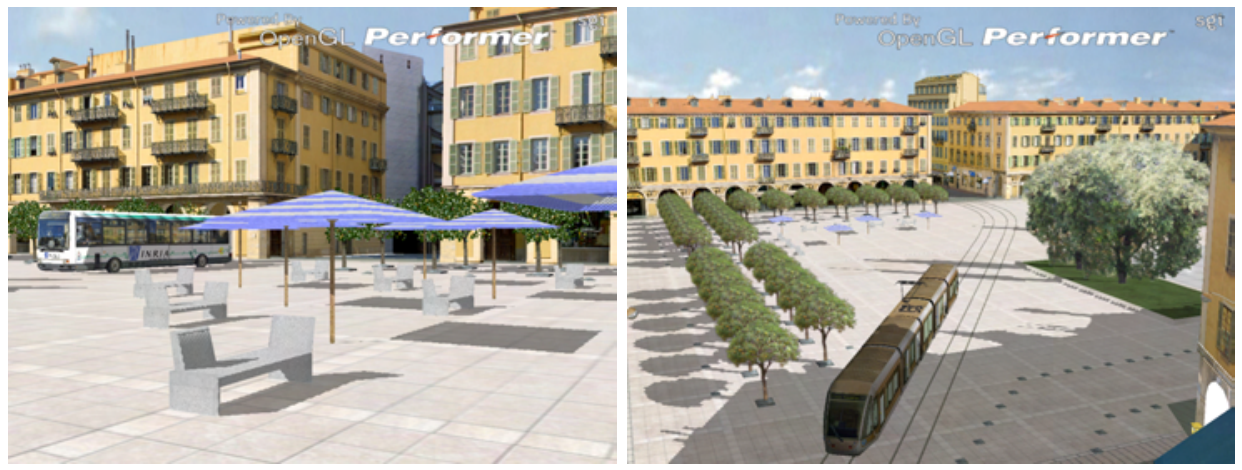

Figure 6: (Left) Simulator snapshot of the perspective view. Note the realism of the captured facades of the buildings, shadows and point-based rendering of trees. (Right) Balcony view of the Place Garibaldi, showing the Tramway passing through the square.

The left hand side contains the "insert" menus, for inserting the 3D models of different elements. The right hand side contains the "operations" on the inserted items, such as "resize", "resize width", "move", "rotate", "select" and "apply". Motion and placement are snapped to a grid in the scene.

The immersive display interface includes a tracked game-controller, or wand, with 12 buttons and a joystick. The 3D model of a rod "extends" the device in the virtual space (Fig. 5). Four of the buttons are used. One is the "action" button used for selec- 
tion of the menu items and for all other selection/deletion/manipulation actions. The remaining three buttons are mapped to the top, perspective and balcony views. At any time during the design session the user can move around in the environment and evaluate the result of her work either in perspective view or "balcony view", allowing a more "overall" view of the current state of the design.

\section{Evaluation}

Our evaluation methodology draws from the structured framework proposed by (Gabbard, Hix, \& SwanII, 1999) (Bowman, Gabbard, \& Hix, 2002) for the design and evaluation of user activity in VEs. This includes the combination of user needs analysis, user task scenarios, and usability evaluation. The user needs analysis was carried out at the very beginning of the project and led to the definition of the user task scenarios that were used in the evaluation sessions.

We performed evaluation of the VE both in a controlled laboratory context and in the natural work environment of the various individuals involved in the real urban planning project. The goal of the controlled experiments was to specifically evaluate the combined effect of realism and interactivity for a real-world urban planning task, as well as the system's usability. The goal of the situated tests was more to observe how non-expert users used the system in the context of real-world usage.

\subsection{Experiment}

\section{Participants}

We have chosen to limit our testing to a small number of users and follow an in-depth qualitative approach. One of the reasons for this is the obvious difficulty in evaluations of real-world situations, i.e., getting busy, highly qualified professionals to agree in participating in experimentation, which requires a significant investment in time. Other reasons include the highly experimental nature of the prototypes and the use of innovative and relatively inaccessible equipment (tracked immersive VR displays) in contexts where these had not been used before.

Thus, we conducted a usability study in the controlled setting of our laboratory with three of the collaborating professional architects, all directly involved in the real Nice Tramway project, and specifically in the design of the new Garibaldi square. Prior to the sessions with the architects, we ran pilot studies with engineers who had no previous VR or computer graphics experience.

\section{Method}

Our evaluation instruments included direct observation, where users performed the various tasks whilst being observed (and videotaped) by a facilitator using a think-aloud pro- 
tocol (Ericsson \& Simon, 1985), a post-experiment questionnaire and post-experiment interviews.

The questionnaire was developed to identify the effect of realism as well as the user's perception of the effectiveness and efficiency of the system, and their level of satisfaction with the interaction. It was constructed by merging a number of standard questionnaires, with questions on a 1-7 Likert scale.

The informal interview that followed the experience aimed at identifying the issues involved in the in situ usage of the system, where the use of a questionnaire does not make sense.

\section{Tasks and Procedure}

The experiment took place on a Barco Baron workbench ${ }^{3}$ with the tracked game controller operating as described previously (Fig. 7). The participant was head-tracked and wore active stereo glasses.

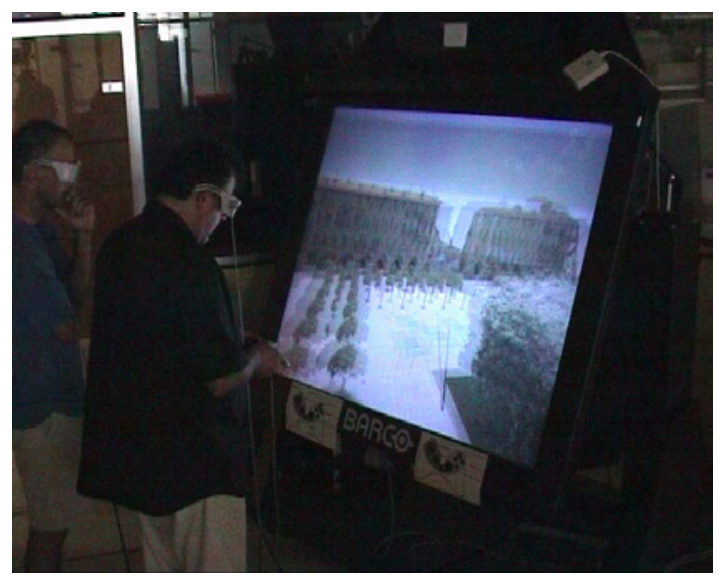

Figure 7: View of a user of the system on the workbench during the experiment (the screen shows the actual stereo display).

The main experiment was preceded by training with a simple virtual environment, using the same interface as in the main experiment. The user practiced in the training environment until she felt comfortable with the interface, typically for 10-15 minutes.

The VE used for the main experiment included the entire environment of the new design of Place Garibaldi (Fig. 1). The users were asked to carry out a set of predefined tasks, which accurately represented the intended actual use of the application, as specified during the user needs analysis. The tasks involved placing, sizing and arranging special tents (umbrellas) and stone benches in three of the four corners of the Place, as seen from above (Fig. 5). Each of the three corners was color-coded with a different

\footnotetext{
${ }^{3}$ The workbench runs on a dual-processor Xeon PC (2.4Ghz), with $1 \mathrm{~Gb}$ of memory, in above-below stereo mode and an NVidia 5950 Ultra graphics card.
} 
colored umbrella and represented, implicitly, a separate sub-task that included different realism features of the VE. In other words, each corner was displayed with a different set of realism enhancements, as follows:

- The sub-task in the lower right corner (blue umbrellas) was displayed with shadows, point-based trees and sound (i.e., visual enhancements and sound).

- The sub-task in the lower left corner (green umbrellas) used "standard" VR quality (i.e., no shadows, no sound, billboard trees, and no crowds).

- The sub-task in the upper left corner (mixed-color umbrellas) was displayed with all enhancements (shadows, point-based trees, sound and crowds).

In this way, the realistic VE enhancements that we developed and wished to evaluate (high-quality shadows, realistic point-based vegetation, 3D sound and crowds) were encoded into the same scene, as part of one experiment. Each user was presented with the top-view at the outset, and was asked to manipulate objects in each one of the corners/color codes in sequence, starting from the lower right. The order in which the levels of realism were tested was pre-determined; we chose to display with enhancements (except crowds) first, then no-enhancements and then all enhancements with crowds, in that order, to avoid an implicit ranking of quality. The user was not explicitly informed of the difference in realism elements, and we attempted to identify their relative importance in the questionnaire.

\subsection{Field Deployment of the System}

In addition to the controlled lab experiments, the system has been used at several different occasions in the context of the real Tramway project. We visited the authorities and the architectural offices at several occasions and report here only the most significant meetings. Specifically, we describe three cases of situated usage: a decision meeting at the city hall, a brainstorming session with the official project working group, and a public event in which different variants for the design of the "Place Garibaldi" were presented.

\subsubsection{City Hall Decision Meeting}

The first case was a discussion of a planned proposal for the choice of the type of trees to be used in the square. The choices included either the 3 meter-high orange trees or the 8-meter high oak (see Fig. 8). As the meeting took place at the Nice City Hall, our VE was presented on a portable system ${ }^{4}$.

\footnotetext{
${ }^{4}$ The system included a laptop with a GeForce4Go graphics card, a portable projector with a stereo loud-speaker based sound system and the standard gamepad-based controller.
} 

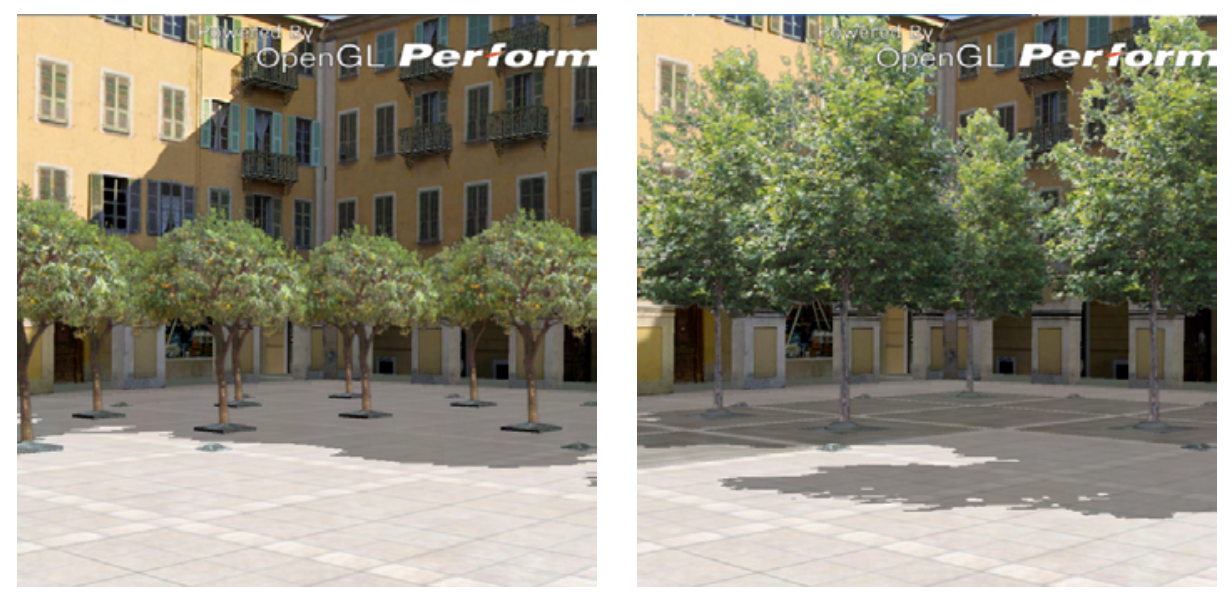

Figure 8: Snapshots of the different solutions for Place Garibaldi, used in the City Hall meeting and the brainstorming session with the architects. Left, the "orange tree" solution; right, the "oak tree" solution. Note how shadow coverage is very different in each.

The working group involved a total of ten persons, mainly high-ranking city officials in charge of public spaces and urban planning, and the architects in charge of the overall project.

The VE included all the realism features of the workbench system. The two scenarios (orange trees and oak trees) were mapped onto two different buttons on the gamepad device, which the members of the working group used in order to explore the different views and locations for the trees, test spatial relationships in the placement of other elements, review the different effect of shadows, etc.

\subsubsection{Brainstorming session}

Another example of field deployment involved the use of the full VE system (tracked stereo-vision workbench) for a brainstorming session. Two of the main architects and a designer participated in this session and used the system as an opportunity to discuss issues concerning the design of the square, most notably the choice of trees and ground elements.

The users visited different angles of the square, examined the different tree options as in the City Hall meeting, and discussed choice of material type and the placement of elements.

\subsubsection{Presentation of Different Options to Officials}

The third case of field deployment was the presentation of the results of the project in a public event. Several high-ranking officials of the project and the municipality were present. The public event coincided in time with a public hearing, held to discuss 

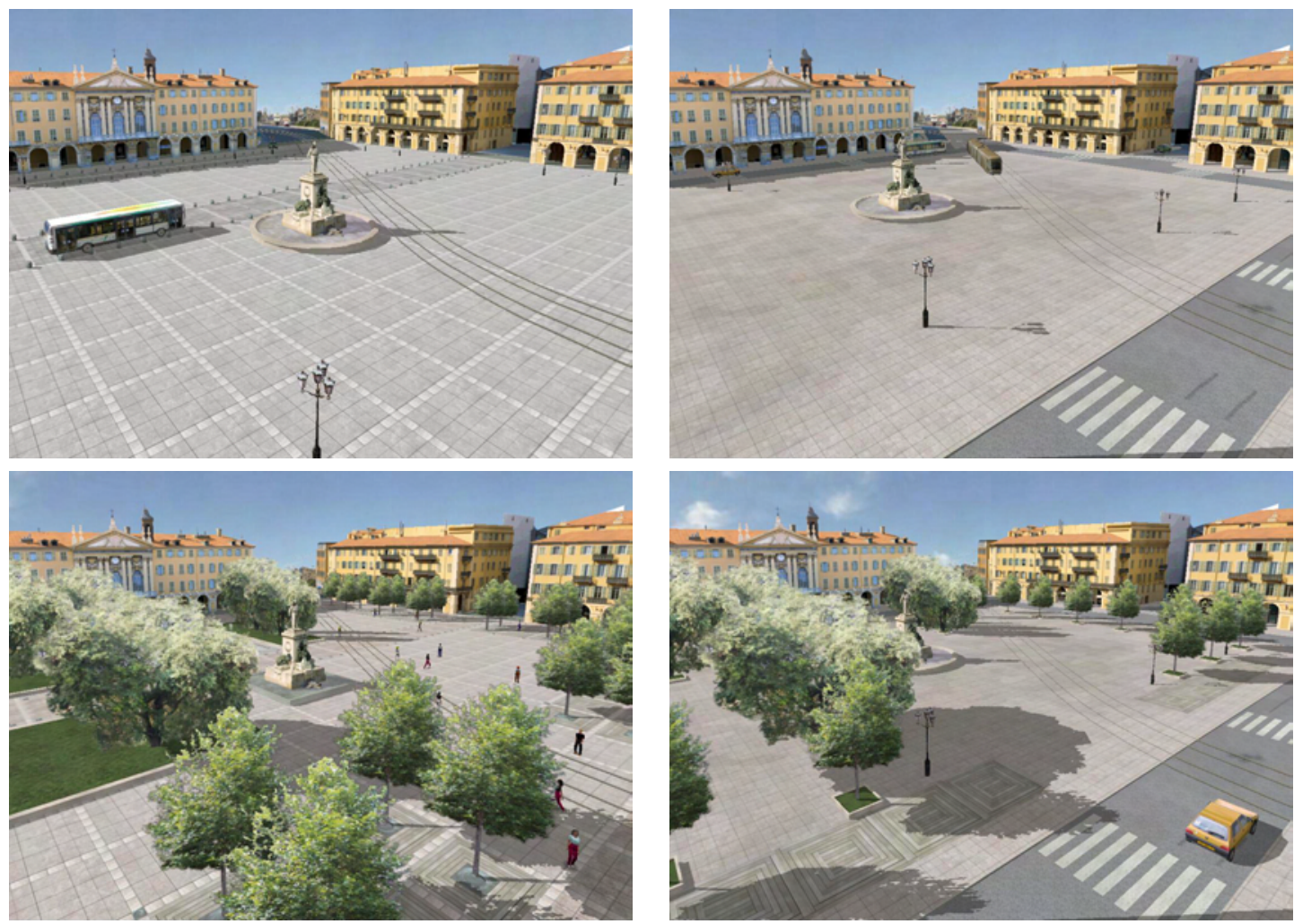

Figure 9: Screenshots of the 4 scenarios used during the presentation to officials.

various options for the square, concerning the questions of vegetation and the presence or absence of cars.

Following sketches of the architects we created a virtual environment showing the four scenarios. These were a "Place d'armes" ("military-style", "stone-only" square) where no trees and no cars are present, a "stone-only" square with cars around the square, a pedestrian square with trees and no cars and a pedestrian square with trees and cars around it, all shown in Fig. 9. The politicians and engineers all used the system to navigate around the VE, both at ground level and in "balcony view", allowing them to evaluate the quality of the design, the effects of noise and sound in the presence/absence of traffic and crowds.

\section{Evaluation Results and Discussion}

\subsection{Observations from the laboratory experiment}

We classify our observations by learnability and ease of use, effectiveness and efficiency, user satisfaction, VE/interface features and realism. Our observations are summarised in Table 1 in the Appendix. 
In terms of learnability and ease of use, the participants ranked the system highly (6.7 average on the Likert scale with a standard deviation of 0.6 for ease of use, 4.7 (2.5) for learning) and stated that they were able to use the tool without difficulty; 2 out of the 3 participants had no experience with interactive 3D systems or video games.

In terms of effectiveness and efficiency, there was strong approval (a mean of 5.0 (1.7) on the Likert scale) of the utility of the tool and the fact that the system would improve productivity in the workplace. The top view, although familiar, was judged useful (mean 5.0 (2.0) on the Likert scale for the top view), while the balcony view was rated as very useful (mean $6.0(1.7)$ ). However, from observing the videos and the interviews, it became clear that manipulation precision was insufficient due to the large distance from the object being manipulated. The solution of a mixed 2D-3D interface was suggested, where a "pen-like" device could be used to directly place objects onto the top-view, as is currently done in existing CAD tools. The need to have the same interface as CAD tools for these tasks was explicitly mentioned by one user. Another participant stated that the perception of ambience and scale were extremely useful and important for an architect in the evaluation of an urban planning project, and found that the tool had great potential for brainstorming.

In terms of user satisfaction, all users stated, both in the questionnaire and during the interviews, that they liked the tool. In the interviews, one user stated a preference for faster response time vs. enhanced realism; also, that one of the main values of the system was that it removes the "break" which exists between traditional 3D CAD systems and the resulting design.

In terms of VE interface features, the balcony view was used extensively. All users agreed that this was a particularly useful view of the environment, and that it helped in their judgement of the resulting design, but also during the design.

Concerning realism, the quality of realism offered by image-based facade textures and the mixed point/polygon-based vegetation were identified as being important, allowing users to better understand the final effect of the placement of trees on the overall design (see Fig. 10, right). The ability to have the true high-quality 3D leaves when zooming in was singled out as being important.

Differences in realism between billboards and point-based trees or the presence/absence of shadows did not show up in the questionnaire ranking. However, in the interviews the users responded that they were concentrating on the task and all identified the importance of shadows for placement and sense of scale but also in terms of appreciation of shadow/sun coverage.

The presence of human figures was judged central (see Fig. 10, left), in particular as a marker of scale. As mentioned before, human figures are used in traditional drawings in this manner (Fig. 3).

The inclusion of spatialized 3D sound was judged as very important to evaluate the overall ambience and atmosphere created by a certain design, in the presence of fountains, the tramway and buses. This was the one item of realism whose presence/absence was noticed by 2 out of 3 participants. 

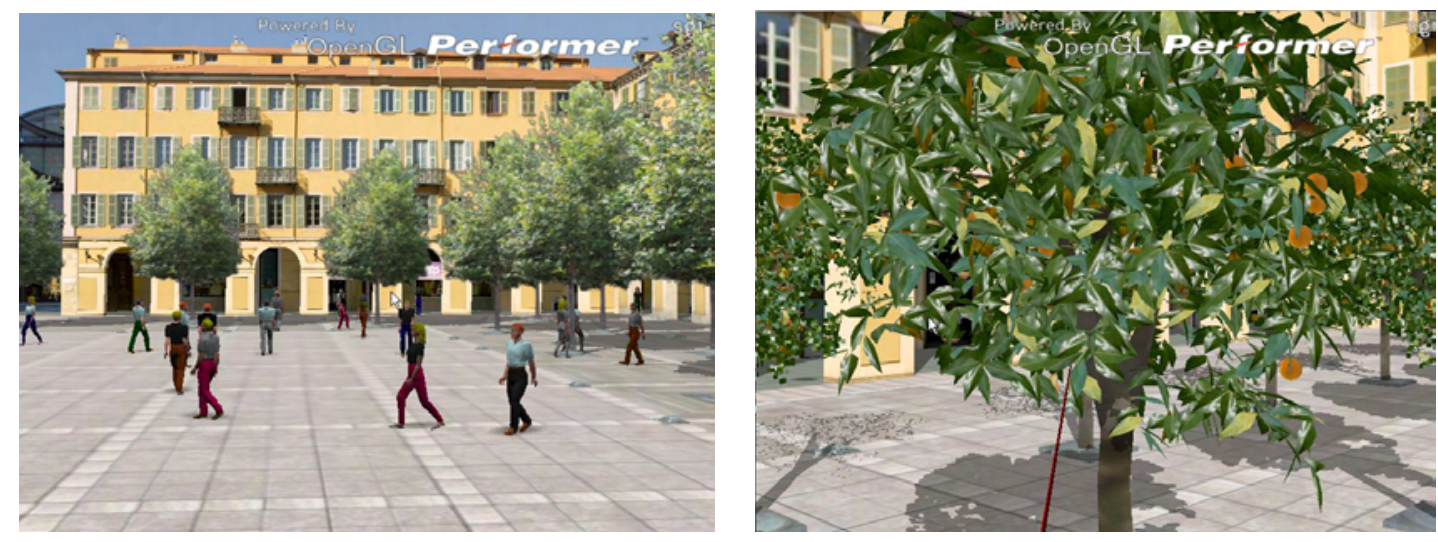

Figure 10: Left: an example with crowds in the Square. Right: Mixed pointbased/polygon trees.

\subsection{Observations from field deployment}

The first interesting observation was that several people at the City Hall meeting considered the representation to be too realistic. The reason stated was that the public would believe that this would be the exact design thus removing all freedom for the realisation of the final project; with drawings, people are more aware of the level of abstraction of the design. Nonetheless, the group considered that this was an excellent tool to help with decision-making and that, with appropriate attention to accuracy in details (e.g., color of stones in the square etc.), it could be used for demonstration purposes. The participants used the different views, singling out the balcony view, and the views with different types of trees, shadows and vegetation and stated that use of the system had brought significant clarification to their understanding of the project.

In the brainstorming session the architects and designer also worked mainly on the choice of trees. However, more time was spent in details, for example the material used to represent ground elements (type of wood/stone etc.), or the spacing between the trees and the choice of their number ( 2 or 3 rows etc.) The tool, as evidenced by observation of their discussions, helped the architects to understand the space and ambience created by their design in a manner which was not previously possible.

In the public event, the engineers and politicians spent half the time at the ground level and half using the balcony view. The users switched between the different scenarios, and were interested in questions of sound and noise at given positions during their walkthroughs of the environment, the effect of shadow coverage, and the sense of scale given through the presence of crowds. At one point the municipal councillor in charge of all transportation issues, declared that things were much clearer and that he now understood the implications of placing trees or a road around the Square. 


\subsection{Discussion}

Our experience reported here indicates that it is important to engage real users in the process of design and evaluation for real-world VEs, despite the difficulties of such a choice (Swan II, Gabbard, Hix, Schulman, \& Kim, 2003). Even though the formal experiment only involved 3 users, a total of about 25 different people used the system in the experiment and in the three in-situ usages described previously. Involving these users allowed us to make better choices, both in the design of the VE and its interface, and provided a wealth of feedback which would have been completely unavailable if we had limited the experiments to graduate students of our institutes.

The second element which we consider important is that of realism. At the outset of the project, we believed that realism is definitely desirable and important. What is more interesting is to see which combination of factors were identified by the users as being important. The sense of scale given by the combination of realistic vegetation and human figures/crowds was an important effect which we had not suspected initially. We were not completely sure how important the presence of 3D sound would be for architects, since they do not have access to such information in their traditional workflow. Our interviews and our observation of the videos indicate that 3D spatialized audio is a central element which allows the architect to better understand the ambience of the design, and better judge the overall result. The 3D sound simulation was also judged very important in the case of multiple scenarios, where the presence of vehicles was a variable of the design. The use of shadows and their importance for the judgement of sun coverage was also a factor whose importance we had initially underestimated. At the outset, we were mainly concerned with the importance of shadows as a good indicator of spatial relationships (Wanger, Ferwerda, \& Greenberg, 1992); the above-mentioned issues were brought up during usage. In general, once attention is drawn to such a fact, high level stimuli can result: the users reported that they felt that the alternative with smaller trees conveyed a sense of being "hotter" than that with the large trees and larger shadows.

It may seem that the request for less realism, expressed in one of the in-situ meetings, contradicts the above. However, we believe that it simply reflects a question of appropriate use of realism, depending on the context. In the specific context where politicians or designers do not wish to make a firm commitment, an artistic depiction may be appropriate; for all other cases cited here, we believe that the need for realism is clear. The idea of conveying a sense of an image as an "artistic impression" rather than a reflection of a future reality, is central to the domain of non-photorealistic rendering (Gooch \& Gooch, 2001), and an interesting direction for future research.

In terms of VR capabilities, multiple views, and in particular the "balcony view" were considered very useful by all users, both in the controlled experiment and in the various in-situ usages. For the users who manipulated the scenes, our interface was judged useful (in particular when positioning and resizing the umbrellas and benches), but the limitations of our prototype design, both in terms of ease of use/precision and in 
terms of latency do not allow significant conclusions on these aspects.

\section{Conclusions}

In this paper we report on a user-centered design in the context of a real-world application. We argue for a combined approach to evaluation in such a context, which uses both "lab experiments" and in-situ real-world usage. Despite the small number of subjects for the controlled experiment, a reasonable number of people (around 25) actually used the system. We believe that we have acquired rich results because they involve an in-depth observation of a real work process, a VE design with the involvement of the actual non-IT domain expert users, and the in situ use in the decision making process of a real project.

To summarize, our study indicates the pertinence of our combined evaluation approach for real-world applications, and the utility of our VE in the context of an urban planning project; that both audio and visual realism, such as 3D sound, shadows and sun coverage, vegetation and crowds, all contribute to better understanding of the VE and aid in the tasks at hand, and finally that VE-specific aspects such as multiple views are important.

In terms of future work, there are many directions to pursue. The interface issues noted by the users (precision in the top-view, etc.) need to be resolved, as well as the issues of latency, by integrating and applying graphics acceleration algorithms (e.g., (Luebke, Watson, Cohen, Reddy, \& Varshney, 2002)). The physical calibration of colors and lighting, an issue brought up at the City Hall meeting, is a valid point for usage in real projects. There are known techniques for color calibration, which use photographs of calibration panels to gamma-correct the displays (Fairchild, 1998). Another interesting direction to explore is the investigation of the use of artistic renderings in VEs (Roussou \& Drettakis, 2003), as well as an equivalent and more challenging approach to rendering sound. Finally, an area of future research is the use of this environment for quantitative experiments investigating specific issues, for example related to audiovisual effects in VEs. The realistic quality of the VE may be important in inducing a strong sense of presence, and thus can be used to help the users concentrate on specific tasks, allowing us to isolate specific variables (for example sound source localization, speed of execution for each task, etc.).

Although this approach of engaging users in the design is time and resource intensive, we consider it to be worthwhile and will continue to explore the application of HCI models into the design of VEs. We believe that our approach, which combines a more controlled evaluation with field deployment, provides promise for the development of environments and tools that can be of real value to their users. This is reinforced by the fact that there has been strong interest in further usage of our VE for future developments in the Tramway project. 


\section{Acknowledgements}

We thank the CANCA, the City of Nice and the Mission Tramway, for accepting this collaboration and providing access to the data and the process. We are indebted to the AURA architects Marc Dalibard, André Jollivet and Emilie Hélardot, who worked with us and generously provided their valuable time and effort for the success of this project. Please note that the images presented in this work do not engage any of the authorities in any way, and that the decision process for the design of the Place is still far from complete. Special thanks are due to Manuel Asselot, Alexandre Olivier, and Franco Tecchia for their contribution in a previous version of this paper. Thanks also to David Geldreich, Emmanuel Gallo and Soteris Stylianou for systems and development help. Thanks also to the generous donation of the Maya software from Autodesk/Alias. This work is part of CREATE, a 3-year RTD project funded by the 5th Framework Information Society Technologies (IST) Programme of the European Union (IST-2001-34231), http://www.cs.ucl.ac.uk/create/http://www.cs.ucl.ac.uk/create/. The authors thank all the individuals from partner institutions that have contributed to the development of the project, and in particular the coordinator Céline Loscos.

\section{References}

Ben-Joseph, E., Ishii, H., Underkoffler, J., Piper, B., \& Yeung, L. (2001). Urban simulation and the luminous planning table bridging the gap between the digital and the tangible. Journal of Planning Education and Research(21), 195-202.

Bowman, D., Gabbard, J. L., \& Hix, D. (2002). A survey of usability evaluation in virtual environments: Classification and comparison of methods. Presence: Teleoperators and Virtual Environments, 11(4), 404-424.

Broll, W., Stoerring, M., \& Mottram, C. (2003). The Augmented Round Table: a new Interface to Urban Planning and Architectural Design. In M. Rauterberg, M. Menozzi, \& J. Wesson (Eds.), Ninth IFIP TC13 International Conference on HCI-INTERACT (p. 1103-1104). Zurich, Switzerland: IOS Publications.

Brooks, F. P. J. (1986). Walkthrough: A dynamic graphics system for simulating virtual buildings. In F. Crow \& S. M. Pizer (Eds.), Workshop on Interactive 3D Graphics (p. 9-21).

Deussen, O., Colditz, C., Stamminger, M., \& Drettakis, G. (2002, October). Interactive visualization of complex plant ecosystems. In Proc. of IEEE Visualization 02.

Drettakis, G., Roussou, M., Tsingos, N., Reche, A., \& Gallo, E. (2004). Image-based Techniques for the Creation and Display of Photorealistic Interactive Virtual Environments. In S. Coquillart \& M. Goebel (Eds.), Eurographics symposium on virtual environments. Grenoble, France.

Ericsson, K. A., \& Simon, H. A. (1985). Protocol Analysis: Verbal Reports as Data. Cambridge, MA.: MIT Press.

Fairchild, M. D. (1998). Color appearance models. Addison Wesley. 
Gabbard, J. L., Hix, D., \& SwanII, J. (1999). User-centered design and evaluation of virtual environments. IEEE Computer Graphics and Applications, 51-59.

Gooch, A., \& Gooch, B. (2001). Non-photorealistic rendering. AK Peters, Ltd. (ISBN: 1568811330, 250 pages)

Houston, M., Niederauer, C., Agrawala, M., \& Humphreys, G. (2004, August). Visualizing dynamic architectural environments. Communications of the ACM, 47(8), 55-59.

Ishii, H., Ben-Joseph, E., Underkoffler, J., Yeung, L., Chak, D., Kanji, Z., et al. (2002, September). Augmented urban planning workbench: Overlaying drawings, physical models and digital simulation. In In IEEE and ACM International Symposium on Mixed and Augmented Reality (ISMAR 2002), Germany.

Jepson, W., \& Friedman, S. (1998). A real-time visualization system for large scale urban environments. http://www.ust.ucla.edu/ bill/UST.html.

Leigh, J., Johnson, A. E., Vasilakis, C. A., \& DeFanti, T. A. (1996). Multi-perspective Collaborative Design in Persistent Networked Virtual Environments. In VRAIS. IEEE.

Luebke, D., Watson, B., Cohen, J. D., Reddy, M., \& Varshney, A. (2002). Level of Detail for 3D Graphics. New York, NY, USA: Elsevier Science Inc.

Mackay, W. E., \& Fayard, A.-L. (1997). HCI, Natural Science and Design: A Framework for Triangulation Across Disciplines. In Designing Interactive Systems (p. 223-234). Amsterdam.

Neale, H., Cobb, S., \& Wilson, J. R. (2002). A Front-Ended Approach to the UserCentred Design of VEs. In IEEE Virtual Reality 2002 (p. 199-206). Orlando, FL: IEEE Computer Society.

Pape, D. E., Imai, T., Anstey, J., Roussou, M., \& DeFanti, T. (1998). XP: An Authoring System for Immersive Art Exhibitions. In 4th International Conference on Virtual Systems and MultiMedia (VSMM) (p. 528-533). Gifu, Japan.

Rauterberg, M., Fjeld, M., Krueger, H., Bichsel, M., Leonhardt, U., \& Meier, M. (1997). BUILD-IT: a video-based interaction technique of a planning tool for construction and design. In H. Miyamoto, S. Saito, M. Kajiyama, \& N. Koizumi (Eds.), Work With Display Units (WWDU'97) (p. 175-176). Tokyo, Japan.

Roussou, M., \& Drettakis, G. (2003, November). Photorealism and Non-Photorealism in Virtual Heritage Representation. In A. Chalmers and D. Arnold and F. Niccolucci (Ed.), VAST 2003 and 1st EG Workshop on Graphics and Cultural Heritage.

Roussou, M., Drettakis, G., Tsingos, N., Reche, A., \& Gallo, E. (2004). A UserCentered Approach on Combining Realism and Interactivity in Virtual Environments. In Ieee virtual reality 2004 (p. 251-252). Chicago, IL: IEEE.

Roussou, M., Sideris, A., Loscos, C., Dettori, A., Drettakis, G., Lombardo, J.-C., et al. (2004). Requirements Analysis on Cultural Heritage - Education and Urban - Architectural Planning and Design Case Studies (Technical Report No. RN/04/09). University College London. 
Sowizral, H., Angus, I. G., Bryson, S., Haas, S., Mine, M. R., \& Pausch, R. (1995). Panel session on Performing Work within Virtual Environments. In 22nd international conference on computer graphics and interactive techniques (p. 497-498).

Stamminger, M., \& Drettakis, G. (2002, July). Perspective shadow maps. In J. Hughes (Ed.), Proceedings of ACM SIGGRAPH 2002. ACM Press/ ACM SIGGRAPH.

Stylianou, S., Fyrillas, M., \& Chrysanthou, Y. (2004, November). Scalable pedestrian simulation for virtual cities. In ACM VRST 2004.

Swan II, J. E., Gabbard, J. L., Hix, D., Schulman, R. S., \& Kim, K. P. (2003). A Comparative Study of User Performance in a Map-Based Virtual Environment. In IEEE Virtual Reality (p. 259-266). Los Angeles, CA: IEEE Computer Society.

Tecchia, F., Loscos, C., \& Chrysanthou, Y. (2002). Visualizing crowds in real-time. Computer Graphics forum, 21(4), 753-756.

Tecchia, F., Loscos, C., Conroy, R., \& Chrysanthou, Y. (2001, January). Agent Behaviour Simulator (ABS): A Platform for Urban Behaviour Development. In GTEC'2001.

Tsingos, N., Gallo, E., \& Drettakis, G. (2004, August). Perceptual audio rendering of complex virtual environments. In Proc. ACM SIGGRAPH 2004.

Wanger, L. C., Ferwerda, J. A., \& Greenberg, D. P. (1992). Perceiving spatial relationships in computer-generated images. IEEE Comput. Graph. Appl., 12(3), 44-51, 54-58.

\section{Appendix}


Table 1: Summary of observations and lessons learned from the evaluation of the VE with users in the laboratory and during field deployment.

\begin{tabular}{|c|c|c|}
\hline Observation categories & Positive user feedback & Drawbacks \\
\hline Learnability and use & $\begin{array}{l}\text { Easy to learn ( } 4.7 \text { on Likert scale) } \\
\text { Highly usable ( } 6.7 \text { on Likert scale) }\end{array}$ & \\
\hline Effectiveness-efficiency & $\begin{array}{l}\text { Approval of utility (5 on Likert scale) } \\
\text { Productivity improvement } \\
\text { Balcony view very useful (not possible otherwise) }\end{array}$ & Insufficient precision of manipulation \\
\hline Satisfaction & $\begin{array}{l}\text { No break btw. activity and resulting design } \\
\text { The ability to immediately "plunge" into the VE }\end{array}$ & Preferred faster response time \\
\hline VE interface & Balcony view most useful for overall design & Insufficient precision in top view \\
\hline Realism & $\begin{array}{l}\text { Image-based facade important } \\
\text { Human figures important measure of scale } \\
\text { Realism in vegetation important } \\
\text { Shadows important for placement, scale, coverage } \\
\text { Sound very important for overall ambience }\end{array}$ & Realism of crowds insufficient \\
\hline
\end{tabular}

